\title{
The added value of quantitative multi-voxel MR spectroscopy in breast magnetic resonance imaging
}

\author{
M. D. Dorrius • R. M. Pijnappel • \\ M. C. van der Weide Jansen • L. Jansen • P. Kappert • \\ M. Oudkerk • P. E. Sijens
}

Received: 23 June 2011 /Revised: 4 October 2011 / Accepted: 6 October 2011 /Published online: 11 November 2011

(C) The Author(s) 2011. This article is published with open access at Springerlink.com

\begin{abstract}
Objective To determine whether quantitative multivoxel MRS improves the accuracy of MRI in the assessment of breast lesions.

Methods Twenty-five consecutive patients with 26 breast lesions $\geq 1 \mathrm{~cm}$ assessed as BI-RADS 3 or 4 with mammography underwent quantitative multivoxel MRS and contrast-enhanced MRI. The choline (Cho) concentration was calculated using the unsuppressed water signal as a concentration reference. ROC analysis established the diagnostic accuracy of MRI and MRS in the assessment of breast lesions.

Results Respective Cho concentrations in 26 breast lesions re-classified by MRI as BI-RADS $2(n=5), 3(n=8), 4(n=$ $5)$ and $5(n=8)$ were $1.16 \pm 0.43$ (mean \pm SD), $1.43 \pm 0.47$, $2.98 \pm 2.15$ and $4.94 \pm 3.10 \mathrm{mM}$. Two BI-RADS 3 lesions and all BI-RADS 4 and 5 lesions were malignant on histopathology and had Cho concentrations between 1.7 and $11.8 \mathrm{mM}(4.03 \pm 2.72 \mathrm{SD})$, which were significantly higher $(P=0.01)$ than that in the 11 benign lesions $(0.4$ $1.5 \mathrm{mM} ; 1.19 \pm 0.33 \mathrm{SD})$. Furthermore, Cho concentrations in the benign and malignant breast lesions in BI-RADS 3 category differed $(P=0.01)$. The accuracy of combined multi-
\end{abstract}

M. D. Dorrius $(\bowtie) \cdot$ R. M. Pijnappel

M. C. van der Weide Jansen - P. Kappert • M. Oudkerk •

P. E. Sijens

Department of Radiology, University Medical Center Groningen,

University of Groningen,

Hanzeplein 1,

9713 GZ Groningen, the Netherlands

e-mail: m.d.dorrius@umcg.nl

\section{Jansen}

Department of Surgery, University Medical Center Groningen,

University of Groningen,

Hanzeplein 1,

9713 GZ Groningen, the Netherlands voxel MRS/breast MRI BI-RADS re-classification (AUC= 1.00) exceeded that of MRI alone (AUC $=0.96 \pm 0.03$ ).

Conclusions These preliminary data indicate that multivoxel MRS improves the accuracy of MRI when using a Cho concentration cut-off $\leq 1.5 \mathrm{mM}$ for benign lesions.

Key Points

- Quantitative multivoxel MR spectroscopy can improve the accuracy of contrast-enhanced breast MRI.

- Multivoxel-MRS can differentiate breast lesions by using the highest Cho-concentration.

- Multivoxel-MRS can exclude patients with benign breast lesions from further invasive diagnostic procedures.

Keywords Magnetic resonance imaging - Spectroscopy · Chemical shift imaging $\cdot$ Breast $\cdot$ Choline

\section{Introduction}

Breast magnetic resonance imaging (MRI) has emerged as an important diagnostic technique. With the use of morphological characteristics and kinetic analysis of the uptake of contrast agents in breast lesions on MRI, the sensitivity of breast MRI approaches $90 \%$ whereas the overall specificity of breast MRI varies between $67 \%$ and $72 \%$ [1-3]. Although the negative predictive value (NPV) of MRI in breast cancer is the highest of all imaging techniques (97\%) [4-6], meaning that in most cases a negative breast MRI can safely rule out malignancy, breast MRI alone is still not the perfect technique.

The fourth edition of the Breast Imaging Reporting and Data System (BI-RADS) Atlas includes a new lexicon for breast MRI that promotes the standardisation of lesion descriptors and assessment categories [7]. This lexicon is 
based on the results of the International Working Group on Breast MRI and the American College of Radiology (ACR) Breast MRI Lexicon Committee and includes a BI-RADS 3 assessment category [7-10]. The guidelines for noninvasive diagnostic tests for breast abnormalities of the Agency for Health Care Research and Quality in the United States (AHRQ) state that the work-up of these probably benign findings is a short-term follow-up or biopsy [11]. At this moment most approaches are intuitive [11, 12]. It can be expected that most patients thus referred for biopsy have a benign lesion.

In addition to morphological and kinetic analysis, metabolic information is considered useful for the assessment of breast lesions. A promising approach to clarifying the precise nature (benign or malignant) of a lesion is the use of a non-invasive MRI method which is referred to as MR spectroscopy $[13,14]$. The diagnostic value of MR spectroscopy is typically based on the detection of elevated levels of choline (Cho) compounds. MR spectroscopic studies of the breast have been either single-voxel [13-33] or multivoxel [34-40] investigations. The single-voxel technique has limitations in terms of lesion coverage. The general practice of including either the entire lesion or just its centre in the voxel, may result in the dilution of the elevated Cho levels in vital malignant tumours by the contributing necrotic and cystic tumour areas with low Cho levels, resulting in false-negative results [34, 38].

The multivoxel MR spectroscopic technique [also known as chemical-shift imaging (CSI)] acquires spectroscopic information from a large volume of interest subdivided into an array of voxels and has the potential to perform truly quantitative tissue characterisation [34-40]. This is necessary because Cho signals are not only detected in malignant breast lesions but also in benign breast lesions and normal fibroglandular tissues [13, 14, 17, 23, 25, 36]. Recently, multivoxel MR spectroscopy was used to measure Cho concentrations encountered in breast lesions [38].

The purpose of this study is to determine whether the Cho level measured by quantitative multivoxel MR spectroscopy can increase the accuracy of contrastenhanced MRI in the assessment of breast lesions.

\section{Materials and methods}

Patient population

This prospective study was conducted between July 2009 and July 2010 at the University Medical Center Groningen and was approved by the Medical Ethical Committee of the University of Groningen. Informed consent was obtained from each patient before participation in the study.
Twenty-five consecutive patients (mean age: 48.7 years, age range: $32-69$ ) with 26 breast lesions $\geq 1 \mathrm{~cm}$ assessed as BI-RADS 3 or BI-RADS 4 with mammography underwent multivoxel MR spectroscopy and contrast-enhanced MRI. Patients were excluded if there was a history of breast cancer, a haematoma of the breast or previous breast surgery including breast implants. The final diagnosis of the breast lesions was based on cytology or histology, considered the gold standard. Tissue samples were obtained by ultrasound-guided fine needle aspiration biopsy (FNAB) $(n=3)$, ultrasound-guided core biopsy $(n=5)$, MR-guided vacuum-assisted core biopsy $(n=1)$ or surgery $(n=17)$.

\section{MR imaging}

Magnetic resonance imaging was performed at $1.5 \mathrm{~T}$ using a whole-body MRI system (Avanto; Siemens Medical Solutions, Erlangen, Germany) with a dedicated bilateral breast coil and the patient in the prone position. The standard MRI protocol included diffusion-weighted imaging (DWI) with $b$-values $0,50,200,500,800$ and $1000 \mathrm{~s} /$ $\mathrm{mm}^{2}$. A T2-weighted turbo spin echo [repetition time (TR)/ echo time (TE) 4500/102 $\mathrm{ms}$, FOV $340 \mathrm{~mm}$ and slice thickness $4 \mathrm{~mm}$ ] was performed in the transversal plane. A T1-weighted three-dimensional (3D) DynaVIEWS sequence (TR/TE/FA $4.17 \mathrm{~ms} / 1.29 \mathrm{~ms} / 10^{\circ}$, FOV $340 \mathrm{~mm}$ and slice thickness $0.97 \mathrm{~mm}$, in total $1.04 \mathrm{~min}$ ) in the transversal plane was made before and seven times after intravenous administration of $0.1 \mathrm{mmol} / \mathrm{kg}$ DOTAREM $(0.5 \mathrm{mmol} \mathrm{Gd} / \mathrm{mL})$. The total duration of the dynamic study was approximately $9 \mathrm{~min}$.

\section{Multivoxel MR spectroscopy}

The breast lesion was localised on DWI and T2-weighted MR images. After the location of the breast lesion was determined, the transverse and sagittal T2-weighted fast spin-echo series covering both breasts (TR/TE 4500/ $102 \mathrm{~ms}$ ) performed without distortion correction were used for MR spectroscopy planning. The spectroscopic imaging protocol [38] included 2D-CSI with point-resolved spectroscopy (PRESS) double spin-echo with phase-encoding gradients between the slice selective $90^{\circ}$ pulse and the first slice-selective optimised $180^{\circ}$ pulse. $2 \mathrm{D}$-CSI of the breast was performed twice, first without suppression of the water and fat signals (TR/TE $1500 / 30 \mathrm{~ms}$ ) to serve as a reference measurement. The second measurement was with suppression of the water and fat signals (TR/TE $1500 / 135 \mathrm{~ms}$ ) and with the same receiver gain. The center of $k$-space was sampled six times in a weighted elliptical fashion resulting in an acquisition time of $4.46 \mathrm{~min}$. The field of view was $8 \times 8 \mathrm{~cm}^{2}$ to roughly cover the transverse cross-section of the examined breast, subdivided into 144 phase encode 
steps to yield voxels of $0.67 \times 0.67 \times 1 \mathrm{~cm}^{3}$ at a slice thickness of $1 \mathrm{~cm}$. In this hybrid CSI technique the volume of interest (VOI), positioned over the suspect lesion, was smaller than the field of view $\left(3 \times 3 \times 1 \mathrm{~cm}^{3}\right)$ in order to end up with essentially measuring the watery part of the breast (glandular breast tissue, histopathology). Six additional nine-lobe sinc outer volume suppression pulses were applied before excitation, resulting in six outer volume suppression slabs of at least $3-\mathrm{cm}$ thick on all sides of the VOI, and unwanted water and lipid signals were suppressed by band-selective inversion with gradient dephasing (BASING) [38]. Automated volume selective (linear plus higher order) shimming resulted in water-signal linewidths of 6 to $9 \mathrm{~Hz}$ for voxels within the VOI.

The multivoxel MR spectroscopy was performed before the T1-weighted images with contrast medium administration to prevent possible interference of metal chelate with the detectability of Cho [41, 42].

Data analysis

\section{MR imaging}

Subtracted images were obtained by subtracting precontrast images from the post-contrast images using commercially available software (CADstream, Confirma Inc., Kirkland WA, USA). MRI were coded using the ordered categories of the ACR BI-RADS lexicon [7]. The MR images were classified as normal if no enhancement was seen in the expected location of the mammographic finding (BI-RADS 1) or if only homogeneous or stippled enhancement was found in the breast, representing normal enhancing breast parenchyma or fibrocystic changes (BIRADS 2). The lesions that were detected on the MRI and which corresponded with the area of the mammographic findings were assessed as focus, mass enhancement or nonmass like enhancement. For the enhancing lesions the location, lesion type, shape, border, distribution, internal enhancement and kinetic curves according to the BI-RADS lexicon were assessed and the lesions were classified as BIRADS 3, 4 or 5 [7].

\section{Multivoxel MR spectroscopy}

In the post-processing $12 \times 12$ phase, encode steps were interpolated into a $16 \times 16$ matrix, i.e. voxels appearing as $0.5 \times 0.5 \times 1 \mathrm{~cm}^{3}$. The number of MR spectroscopic peaks fitted included the chemical shift ranges restricted to $3.1-$ $3.3 \mathrm{ppm}$ for Cho, $4.5-5.0 \mathrm{ppm}$ for water and $1.0-1.5 \mathrm{ppm}$ for the main resonance of fat $\left(-\mathrm{CH}_{2}-\right)$. Standardised postprocessing protocols were used for processing the raw data automatically, allowing for operator-independent quantifications. The postprocessing protocol for the water and fat suppressed series included Hanning filtering (width $700 \mathrm{~ms}$, center $0 \mathrm{~ms}$ ), zero filling from 512 to 1024 data points, Fourier transformation, polynomial baseline correction (with the above peak ranges excluded), phase correction and frequency-domain curve fitting to Gaussian lineshapes using the standard Singo software provided by the manufacturer of the MRI system.

For each lesion the highest concentration of the metabolite Cho amongst the various corresponding voxels was calculated from the relative peak areas of the resonances of Cho $\left[\mathrm{N}\left(\mathrm{CH}_{3}\right)_{3}\right.$ at $\left.3.23 \mathrm{ppm}\right]$, denoted $S_{\mathrm{Cho}}$, and water $\left(\mathrm{H}_{2} \mathrm{O}\right.$ at $\left.4.7 \mathrm{ppm}\right)$ using Eq. (1):

$$
\begin{aligned}
{\left[S_{\mathrm{Cho}}\right]=} & S_{\mathrm{Cho}} / S_{\mathrm{H}_{2} \mathrm{O}} \times \mathrm{TWC} \times 1 / \mathrm{Mw}_{\mathrm{H}_{2} \mathrm{O}} \times n_{\mathrm{H}_{2} \mathrm{O}} / n_{\mathrm{Cho}} \\
& \times \mathrm{T} 1 \mathrm{sat}_{\mathrm{H}_{2} \mathrm{O}} / \mathrm{T} 1 \mathrm{sat} \\
\mathrm{Cho} & \times \mathrm{T} 2 \mathrm{sat}_{\mathrm{H}_{2} \mathrm{O}} / \mathrm{T} 2 \mathrm{sat}_{\mathrm{Ch}}
\end{aligned}
$$

To express concentrations in molar units ( $\mathrm{mol} / \mathrm{L}$ of tissue volume), literature values were adapted for the tissue water contents (TWC) of voxels containing breast tumour tissue, $82 \%$ [28]: the number of protons in the water molecule, $n_{\mathrm{H}_{2} \mathrm{O}}$, is 2 , and that in the Cho group, $n_{\mathrm{Cho}}$, is $9 . \mathrm{Mw}_{\mathrm{H}_{2} \mathrm{O}}$ represents the molecular weight of water.

The $\mathrm{T} 1$ and $\mathrm{T} 2$ saturation factors for water and Cho were calculated using literature values for $\mathrm{T} 1$ and $\mathrm{T} 2$ relaxation times of water and Cho as described elsewhere [38].

\section{Statistical analysis}

Breast lesions that MRI classified as BI-RADS 2 were considered benign and BI-RADS 3, 4 and 5 lesions were considered positive for malignancy. Sensitivity, specificity, positive predictive values (PPV), and negative predictive values (NPV) of breast contrast-enhanced MRI were calculated on the basis of final histopathology reports.

The mean and standard deviation of the highest Cho concentration of all benign and malignant lesions were calculated. Differences between the highest Cho measurements of benign and malignant breast lesions were tested for significance using the independent sample T test. A $P$ value $<0.05$ was considered as statistically significant. Receiver operating characteristics (ROC) analysis was used to quantify the diagnostic accuracy of contrast-enhanced MRI and multivoxel MR spectroscopy in the assessment of breast lesions. Data were analysed in SPSS 16.0 (SPSS, Chicago, IL, USA) and STATA SE version 11.0 (STATA, College Station, TX, USA).

\section{Results}

The indication for undergoing mammographic examination was a palpable breast lesion in $17(68.0 \%)$ patients. In 3 $(12.0 \%)$ patients a suspicious lesion was found during the 
National Dutch Breast Cancer Screenings Programme. Three $(12.0 \%)$ patients were screened because of a high risk of breast cancer. Two $(8.0 \%)$ patients had a mammography because of an enlarged lymph node in the axilla.

\section{Breast lesions}

Twenty-six breast lesions were assessed (1 patient had both a mammographic BI-RADS 3 lesion and a BI-RADS 4 lesion in the same breast). Ten (38.5\%) out of 26 breast lesions were classified as BI-RADS 3 and $16(61.5 \%)$ breast lesions as BI-RADS 4 on the mammogram. The size of the benign lesions as seen on MRI varied between 10 and $21 \mathrm{~mm}$. For malignant lesions the size was 10 to $80 \mathrm{~mm}$.

MRI BI-RADS classification and multivoxel MR spectroscopy

Magnetic resonance imaging re-classified the 26 breast lesions as BI-RADS $2(n=5 ; 19.2 \%)$, BI-RADS $3(n=8$; $30.8 \%)$, BI-RADS $4(n=5 ; 19.2 \%)$ and BI-RADS $5(n=8$; $30.8 \%$ ). The means of the highest Cho concentrations detected in these BI-RADS categories were $1.16 \pm 0.43 \mathrm{SD}$ for five BI-RADS 2 lesions, $1.43 \pm 0.47 \mathrm{SD}$ for eight BIRADS 3 lesions, 2.98 \pm 2.15 SD for five BI-RADS 4 lesions and 4.94 \pm 3.10 SD for eight BI-RADS 5 lesions (Table 1).

The five MRI BI-RADS 2 lesions with a mean Cho concentration of $1.16 \mathrm{mM}$ were benign: 3 were fibroadenomas and 2 showed no malignant cells after FNAB.

Two out of eight MRI BI-RADS 3 lesions turned out to be malignant and showed a mean Cho concentration of $2.05 \mathrm{mM}$. These two breast lesions were an invasive ductal carcinoma and an invasive lobular carcinoma. The other six MRI BI-RADS 3 lesions were benign and had a mean Cho concentration of $1.22 \mathrm{mM}$. One out of 6 benign breast lesions showed no malignant cells in the FNAB and the histologies of the other five lesions were: 2 fibroadenomas, lobular hyperplasia without atypia, epithelial hyperplasia without atypia and fibrosis with apocrine metaplasia. There was a significant difference in Cho concentration between the benign and malignant breast lesions in the BI-RADS 3 category $(P=0.01)$.

All five MRI BI-RADS 4 lesions and all eight MRI BIRADS 5 lesions with a mean Cho concentration of $2.98 \mathrm{mM}$ and $4.94 \mathrm{mM}$, respectively, showed malignancy after surgery: 10 invasive ductal carcinomas, 2 invasive lobular carcinoma (Fig. 1) and 1 metaplastic carcinoma.

Furthermore, there was no overlap between the ranges in benign [0.4-1.5 $\mathrm{mM}(1.19 \pm 0.33 \mathrm{SD})]$ and malignant lesions [1.7-11.8 mM (4.03 $\pm 2.72 \mathrm{SD})]$ (Tables 1, 2).

Breast MRI without multivoxel MR spectroscopy had a sensitivity of $100 \%$, specificity of $45.5 \%$, PPV of $71.4 \%$ and NPV of $100 \%$. ROC analysis revealed an area under the curve (AUC) of $0.96 \pm 0.03 \quad(95 \%$ CI: 0.91-1.00) for the accuracy of breast MRI in the assessment of breast lesions. Using a threshold of the Cho concentration of $1.5 \mathrm{mM}$ as the distinction between benign and malignant lesions, the ROC analysis for multivoxel MR spectroscopy revealed an AUC of 1.00 (95\% CI: 1.00-1.00) (Fig. 2).

\section{Discussion}

Breast MRI is an important diagnostic technique and with an NPV of 97\% [4-6] it can safely exclude malignancy. Also, in this study the NPV of breast MRI is very high $(100 \%)$ and therefore no further invasive diagnostic workup is needed when breast lesions are assessed as BI-RADS 2 with MRI. However, breast MRI is still not perfect. Today BI-RADS is the communication tool in breast MRI reports and the most difficult breast lesions are those that are classified as BI-RADS 3 with MRI. The probability of a mammographic BI-RADS 3 lesion being cancerous is considered to be less than $2 \%$ by AHQR [11], but the acceptable cancer yield is not clearly defined for MRI BIRADS 3 lesions. There are five articles that included data in the MRI BI-RADS 3 assessment category, with a resulting wide range of cancer yields $(0.6-10 \%)$ [4, 43-46].

Table 1 MRI BI-RADS classification, number of voxels and the mean and standard deviation (SD) of the highest Cho concentration in benign and malignant breast lesions

\begin{tabular}{|c|c|c|c|c|c|}
\hline \multirow{2}{*}{$\begin{array}{l}\text { MRI BI-RADS classification } \\
\text { (number of benign }+ \text { malignant lesions) }\end{array}$} & \multirow{2}{*}{$\begin{array}{l}\text { Number of } \\
\text { voxels (range) }\end{array}$} & \multicolumn{4}{|c|}{ Highest Cho concentration $(\mathrm{mM})($ mean $\pm \mathrm{SD})$} \\
\hline & & All & Benign & Malignant & $P$ value \\
\hline 5 BI-RADS 2 lesions $(5+0)$ & $2-6$ & $1.16 \pm 0.43$ & $1.16 \pm 0.43$ & & \\
\hline 8 BI-RADS 3 lesions $(6+2)$ & $2-6$ & $1.43 \pm 0.47$ & $1.22 \pm 0.26$ & $2.05 \pm 0.35$ & 0.01 \\
\hline 5 BI-RADS 4 lesions $(0+5)$ & $2-7$ & $2.98 \pm 2.15$ & & $2.98 \pm 2.15$ & \\
\hline 8 BI-RADS 5 lesions $(0+8)$ & $3-14$ & $4.94 \pm 3.10$ & & $4.94 \pm 3.10$ & \\
\hline Total & & $1.19 \pm 0.33$ & & $4.03 \pm 2.72$ & 0.01 \\
\hline
\end{tabular}



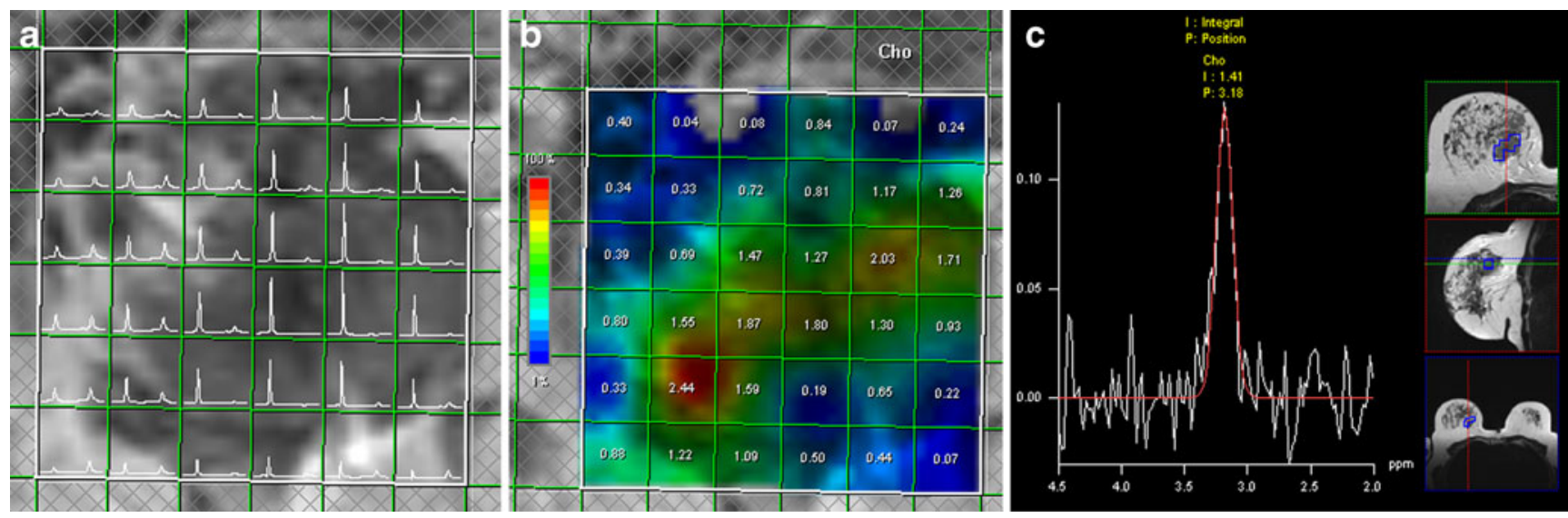

Fig. 1 Volume of interest (36 voxels of $0.25 \mathrm{~cm}^{3}$ each) centred on an invasive lobular carcinoma in the right breast of a 67 -year-old patient and spectral map showing intense water and minor fat peaks in the lesion (a). This array of unsuppressed spectra is shown for the chemical shift range of $0-6 \mathrm{ppm}$. After application of water and fat

Although the diagnostic work-up of a BI-RADS 3 lesion can be a biopsy (instead of a follow-up breast MRI after suppression intense Cho signals are detected in the whole lesion as shown in green on the metabolic map (b). The highest detected Cho level (the red voxel on the metabolic map) is used for quantification. The sum of all tumour MR spectra together is shown in (c) where the fit for Cho is shown in red (range 2-4.5 ppm)

6 months) over $90 \%$ of patients who are referred for biopsy have a benign disease.

Table 2 Mammographic and MRI BI-RADS classification, number of voxels, the highest Cho concentration and histopathology for 26 breast lesions

\begin{tabular}{|c|c|c|c|c|}
\hline $\begin{array}{l}\text { Mammographic } \\
\text { BI-RADS category }\end{array}$ & $\begin{array}{l}\text { MRI BI-RADS } \\
\text { category }\end{array}$ & $\begin{array}{l}\text { No. of } \\
\text { voxels }\end{array}$ & $\begin{array}{l}\text { Highest Cho } \\
\text { concentration }(\mathrm{mmol} / \mathrm{L})\end{array}$ & Histopathology \\
\hline \multirow[t]{10}{*}{10 BI-RADS 3} & \multirow[t]{4}{*}{4 BI-RADS 2} & 6 & 0.4 & Fibroadenoma \\
\hline & & 2 & 1.3 & Fibroadenoma \\
\hline & & 2 & 1.3 & No malignant cells \\
\hline & & 4 & 1.5 & No malignant cells \\
\hline & \multirow[t]{5}{*}{5 BI-RADS 3} & 6 & 1.3 & Fibroadenoma \\
\hline & & 2 & 1.3 & Fibroadenoma \\
\hline & & 4 & 1.5 & Fibrosis with apocrine metaplasia \\
\hline & & 4 & 1.0 & Lobular hyperplasia without atypia \\
\hline & & 4 & 0.8 & No malignant cells \\
\hline & 1 BI-RADS 4 & 4 & 2.4 & Invasive ductal carcinoma \\
\hline \multirow[t]{16}{*}{16 BI-RADS 4} & 1 BI-RADS 2 & 2 & 1.3 & Fibroadenoma \\
\hline & \multirow[t]{3}{*}{3 BI-RADS 3} & 5 & 1.4 & Epithelial hyperplasia without atypia \\
\hline & & 2 & 1.8 & Invasive ductal carcinoma \\
\hline & & 2 & 2.3 & Invasive lobular carcinoma \\
\hline & \multirow[t]{4}{*}{4 BI-RADS 4} & 2 & 1.7 & Invasive ductal carcinoma \\
\hline & & 2 & 1.8 & Invasive ductal carcinoma \\
\hline & & 3 & 2.2 & Invasive ductal carcinoma \\
\hline & & 7 & 6.8 & Invasive ductal carcinoma \\
\hline & \multirow[t]{8}{*}{8 BI-RADS 5} & 3 & 2.5 & Invasive ductal carcinoma \\
\hline & & 4 & 4.1 & Invasive ductal carcinoma \\
\hline & & 4 & 2.4 & Invasive ductal carcinoma \\
\hline & & 6 & 4.6 & Invasive ductal carcinoma \\
\hline & & 4 & 6.8 & Invasive ductal carcinoma \\
\hline & & 5 & 11.8 & Invasive lobular carcinoma \\
\hline & & 14 & 3.4 & Invasive lobular carcinoma (Fig. 1) \\
\hline & & 7 & 3.9 & Metaplastic carcinoma \\
\hline
\end{tabular}




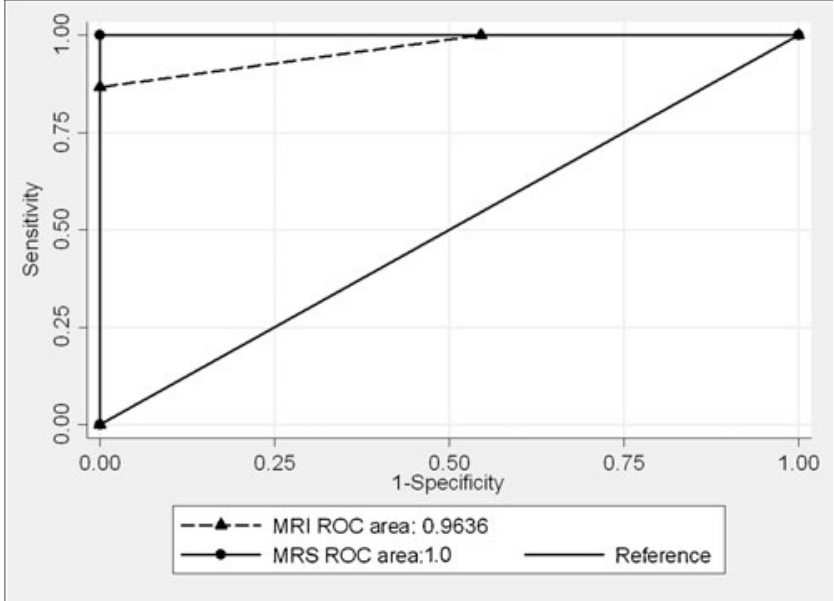

Fig. 2 ROC curves for the comparison of breast MRI and multivoxel MR spectroscopy in the assessment of breast lesions. There was a significant difference in the Cho concentrations between all benign and malignant lesions $(P=0.01)$

This present study indicates that the non-invasive quantitative multivoxel MR spectroscopic technique can be an additional tool to contrast-enhanced MRI in the assessment of breast lesions. The accuracy of breast MRI is excellent, but according to our preliminary results multivoxel MR spectroscopy shows an AUC of 1.00. There was no overlap between the outcomes of benign and malignant lesions for the highest Cho concentration, $0.4-1.5 \mathrm{mM}$ and $1.7-11.8 \mathrm{mM}$, respectively. Cho concentrations over $1.5 \mathrm{mM}$ are not found in benign lesions, such as fibroadenomas. In our study benign breast lesions that were classified as BI-RADS 3 with MRI had a highest Cho concentration $\leq 1.5 \mathrm{mM}$ and were significantly different $(P=0.01)$ from the two malignant BI-RADS 3 lesions. In this way patients with benign BI-RADS 3 lesions can be excluded from further invasive diagnostic work-ups. Accordingly, it can be expected that the added value of non-invasive multivoxel MR spectroscopy applies to the MRI-classified BI-RADS 3 lesions.

There are only three previous studies featuring the diagnostic value of combined contrast-enhanced MRI and multivoxel MR spectroscopy in evaluating breast lesions. The conclusion of these three studies is that multivoxel MR spectroscopy appears to be a promising technique for the classification of breast lesions when contrast-enhanced MRI results are equivocal. Since the goal of contrast-enhanced MRI is to reach high sensitivity at the cost of specificity, the metabolic information measured by multivoxel MR spectroscopy may be used to improve the specificity in the diagnosis of breast tumours [34, 36, 37]. In the study of
Baek et al. [34] multivoxel MR spectroscopy had a sensitivity of $81 \%$, specificity of $78 \%$ and overall accuracy of $81 \%$ with the use of ROC analysis. These outcomes show lower sensitivity and specificity than the results in our study. A limitation of the three studies is that the area of the Cho was measured in the lesion and expressed relative to the background noise level (signal-to-noise ratio), which is not a quantitative measurement of Cho [34, 36, 37]. In our quantitative multivoxel MR spectroscopic study the detectability of abnormalities in the Cho level is improved by the measurement of the highest lesion Cho concentration with the ability to analyse the regional distribution of tumour metabolites.

A limitation of our study is that a small patient population is included. Another limitation is that only breast lesions $\geq 1 \mathrm{~cm}^{3}$ were included, reflecting the limited sensitivity of MR spectroscopy (voxels sixes were $0.25 \mathrm{~cm}^{3}$ ). Smaller breast lesions will have the problem that the measured lesion Cho levels are reduced by partial volume effects, reducing the changes of being able to demonstrate a malignant Cho profile. In the future, the use of more sensitive MRI systems operating at $3 \mathrm{~T}$ and higher may be expected to allow for the inclusion of smaller lesions. Also, in this study the breast lesions were measured by MR spectroscopy with DWI and T2weighted imaging based positioning of the VOI and not planned on the contrast-enhanced T1-weighted images, acquired after the MR spectroscopy to avoid the likely influence of contrast medium on the measured Cho concentration. This can be a problem if the breast lesion is not visible with the first two sequences (DWI and T2). Furthermore, the methodology of this study has some technical limitations regarding partial volume effects, water and fat suppression, whole breast coverage in acceptable imaging times and quantification. Nevertheless, in this quantitative multivoxel MR spectroscopic study Cho concentrations are measured more accurately and a significant difference $(P=0.01)$ between benign and malignant lesions for the highest Cho concentration is shown.

In conclusion, this study indicates that the noninvasive quantitative multivoxel MR spectroscopic technique can improve the accuracy of contrast-enhanced MRI in the assessment of breast lesions, especially for breast lesions classified as BI-RADS 3. A Cho concentration over $1.5 \mathrm{mM}$ was not found in benign breast lesions with a volume $\geq 1 \mathrm{~cm}^{3}$ and therefore these lesions can be excluded from further diagnostic work-up. Nevertheless, larger patient samples are needed to reinforce these conclusions. 
Open Access This article is distributed under the terms of the Creative Commons Attribution Noncommercial License which permits any noncommercial use, distribution, and reproduction in any medium, provided the original author(s) and source are credited.

\section{References}

1. Bluemke DA, Gatsonis CA, Chen MH, DeAngelis GA, DeBruhl $\mathrm{N}$, Harms S, Heywang-Kobrunner SH, Hylton N, Kuhl CK, Lehman C, Pisano ED, Causer P, Schnitt SJ, Smazal SF, Stelling CB, Weatherall PT, Schnall MD (2004) Magnetic resonance imaging of the breast prior to biopsy. JAMA 292:2735-2742

2. Hrung JM, Sonnad SS, Schwartz JS, Langlotz CP (1999) Accuracy of MR imaging in the work-up of suspicious breast lesions: a diagnostic meta-analysis. Acad Radiol 6:387-397

3. Peters NH, Borel Rinkes IH, Zuithoff NP, Mali WP, Moons KG, Peeters PH (2008) Meta-analysis of MR imaging in the diagnosis of breast lesions. Radiology 246:116-124

4. Kuhl CK, Schmutzler RK, Leutner CC, Kempe A, Wardelmann E, Hocke A, Maringa M, Pfeifer U, Krebs D, Schild HH (2000) Breast MR imaging screening in 192 women proved or suspected to be carriers of a breast cancer susceptibility gene: preliminary results. Radiology 215:267-279

5. Moy L, Elias K, Patel V, Lee J, Babb JS, Toth HK, Mercado CL (2009) Is breast MRI helpful in the evaluation of inconclusive mammographic findings? AJR Am J Roentgenol 193:986-993

6. Vassiou K, Kanavou T, Vlychou M, Poultsidi A, Athanasiou E, Arvanitis DL, Fezoulidis IV (2009) Characterization of breast lesions with CE-MR multimodal morphological and kinetic analysis: comparison with conventional mammography and high-resolution ultrasound. Eur J Radiol 70:69-76

7. American College of Radiology (ACR): Illustrated breast imaging reporting and data system (BI-RADS), 1998. http://www.acr.org/ SecondaryMainMenuCategories/quality_safety/BIRADSAtlas/ BIRADSAtlasexcerptedtext.aspx

8. Ikeda DM, Baker DR, Daniel BL (2000) Magnetic resonance imaging of breast cancer: clinical indications and breast MRI reporting system. J Magn Reson Imaging 12:975-983

9. Ikeda DM, Hylton NM, Kinkel K, Hochman MG, Kuhl CK, Kaiser WA, Weinreb JC, Smazal SF, Degani H, Viehweg P, Barclay J, Schnall MD (2001) Development, standardization, and testing of a lexicon for reporting contrast-enhanced breast magnetic resonance imaging studies. J Magn Reson Imaging 13:889-895

10. Ikeda DM (2001) Progress report from the American College of Radiology Breast MR Imaging Lexicon Committee. Magn Reson Imaging Clin N Am 9:295-302

11. Agency for Health Care Research and Quality Effectiveness of non-invasive diagnostic test for breast abnormalities. AHRQ publication no. 06-EHC005-EF, 2006, 2009. http://www.ahrq.gov/

12. Tardivon AA, Athanasiou A, Thibault F, El KC (2007) Breast imaging and reporting data system (BIRADS): magnetic resonance imaging. Eur J Radiol 61:212-215

13. Bartella L, Morris EA, Dershaw DD, Liberman L, Thakur SB, Moskowitz C, Guido J, Huang W (2006) Proton MR spectroscopy with choline peak as malignancy marker improves positive predictive value for breast cancer diagnosis: preliminary study. Radiology 239:686-692

14. Bartella L, Thakur SB, Morris EA, Dershaw DD, Huang W, Chough E, Cruz MC, Liberman L (2007) Enhancing nonmass lesions in the breast: evaluation with proton $(1 \mathrm{H})$ MR spectroscopy. Radiology 245:80-87

15. Baek HM, Chen JH, Nalcioglu O, Su MY (2008) Proton MR spectroscopy for monitoring early treatment response of breast cancer to neo-adjuvant chemotherapy. Ann Oncol 19:1022-1024

16. Baik HM, Su MY, Yu H, Mehta R, Nalcioglu O (2006) Quantification of choline-containing compounds in malignant breast tumors by $1 \mathrm{H}$ MR spectroscopy using water as an internal reference at 1.5 T. MAGMA 19:96-104

17. Bolan PJ, Meisamy S, Baker EH, Lin J, Emory T, Nelson M, Everson LI, Yee D, Garwood M (2003) In vivo quantification of choline compounds in the breast with 1H MR spectroscopy. Magn Reson Med 50:1134-1143

18. Cecil KM, Schnall MD, Siegelman ES, Lenkinski RE (2001) The evaluation of human breast lesions with magnetic resonance imaging and proton magnetic resonance spectroscopy. Breast Cancer Res Treat 68:45-54

19. Gribbestad IS, Singstad TE, Nilsen G, Fjosne HE, Engan T, Haugen OA, Rinck PA (1998) In vivo 1H MRS of normal breast and breast tumors using a dedicated double breast coil. J Magn Reson Imaging 8:1191-1197

20. Huang W, Fisher PR, Dulaimy K, Tudorica LA, O'Hea B, Button TM (2004) Detection of breast malignancy: diagnostic MR protocol for improved specificity. Radiology 232:585-591

21. Jagannathan NR, Kumar M, Seenu V, Coshic O, Dwivedi SN, Julka PK, Srivastava A, Rath GK (2001) Evaluation of total choline from in-vivo volume localized proton MR spectroscopy and its response to neoadjuvant chemotherapy in locally advanced breast cancer. Br J Cancer 84:1016-1022

22. Joe BN, Chen VY, Salibi N, Fuangtharntip P, Hildebolt CF, Bae KT (2005) Evaluation of 1H-magnetic resonance spectroscopy of breast cancer pre- and postgadolinium administration. Invest Radiol 40:405-411

23. Kvistad KA, Bakken IJ, Gribbestad IS, Ehrnholm B, Lundgren S, Fjosne HE, Haraldseth O (1999) Characterization of neoplastic and normal human breast tissues with in vivo (1)H MR spectroscopy. J Magn Reson Imaging 10:159-164

24. Lee J, Yamaguchi T, Abe A, Shizukuishi K, Uemura H, Miyagi E, Sakata K, Inoue T (2004) Clinical evaluation of choline measurement by proton MR spectroscopy in patients with malignant tumors. Radiat Med 22:148-154

25. Roebuck JR, Cecil KM, Schnall MD, Lenkinski RE (1998) Human breast lesions: characterization with proton MR spectroscopy. Radiology 209:269-275

26. Stanwell P, Gluch L, Clark D, Tomanek B, Baker L, Giuffre B, Lean C, Malycha P, Mountford C (2005) Specificity of choline metabolites for in vivo diagnosis of breast cancer using $1 \mathrm{H}$ MRS at 1.5 T. Eur Radiol 15:1037-1043

27. Yeung DK, Cheung HS, Tse GM (2001) Human breast lesions: characterization with contrast-enhanced in vivo proton MR spectroscopy initial results. Radiology 220:40-46

28. Baek HM, Chen JH, Nie K, Yu HJ, Bahri S, Mehta RS, Nalcioglu O, Su MY (2009) Predicting pathologic response to neoadjuvant chemotherapy in breast cancer by using MR imaging and quantitative $1 \mathrm{H}$ MR spectroscopy. Radiology 251:653-662

29. Sardanelli F, Fausto A, Di Leo G, de Nijs R, Vorbuchner M, Podo F (2009) In vivo proton MR spectroscopy of the breast using the total choline peak integral as a marker of malignancy. AJR Am J Roentgenol 192:1608-1617

30. Tozaki M, Fukuma E (2009) 1H MR spectroscopy and diffusionweighted imaging of the breast: are they useful tools for 
characterizing breast lesions before biopsy? AJR Am J Roentgenol 193:840-849

31. Tse GM, Cheung HS, Pang LM, Chu WC, Law BK, Kung FY, Yeung DK (2003) Characterization of lesions of the breast with proton MR spectroscopy: comparison of carcinomas, benign lesions, and phyllodes tumors. AJR Am J Roentgenol 181:1267-1272

32. Yeung DK, Yang WT, Tse GM (2002) Breast cancer: in vivo proton MR spectroscopy in the characterization of histopathologic subtypes and preliminary observations in axillary node metastases. Radiology 225:190-197

33. Bakken IJ, Gribbestad IS, Singstad TE, Kvistad KA (2001) External standard method for the in vivo quantification of cholinecontaining compounds in breast tumors by proton MR spectroscopy at 1.5 Tesla. Magn Reson Med 46:189-192

34. Baek HM, Chen JH, Yu HJ, Mehta R, Nalcioglu O, Su MY (2008) Detection of choline signal in human breast lesions with chemical-shift imaging. J Magn Reson Imaging 27:1114-1121

35. Geraghty PR, van den Bosch MA, Spielman DM, Hunjan S, Birdwell RL, Fong KJ, Stables LA, Zakhour M, Herfkens RJ, Ikeda DM (2008) MRI and (1)H MRS of the breast: presence of a choline peak as malignancy marker is related to $\mathrm{K} 21$ value of the tumor in patients with invasive ductal carcinoma. Breast J 14:574-580

36. Jacobs MA, Barker PB, Bottomley PA, Bhujwalla Z, Bluemke DA (2004) Proton magnetic resonance spectroscopic imaging of human breast cancer: a preliminary study. J Magn Reson Imaging 19:68-75

37. Jacobs MA, Barker PB, Argani P, Ouwerkerk R, Bhujwalla ZM, Bluemke DA (2005) Combined dynamic contrast enhanced breast MR and proton spectroscopic imaging: a feasibility study. J Magn Reson Imaging 21:23-28

38. Sijens PE, Dorrius MD, Kappert P, Baron P, Pijnappel RM, Oudkerk M (2010) Quantitative multivoxel proton chemical shift imaging of the breast. Magn Reson Imaging 28:314-319
39. Stanwell P, Mountford C (2007) In vivo proton MR spectroscopy of the breast. Radiographics 27:S253-S266

40. Su MY, Baik HM, Yu HJ, Chen JH, Mehta RS, Nalcioglu O (2006) Comparison of choline and pharmacokinetic parameters in breast cancer measured by MR spectroscopic imaging and dynamic contrast enhanced MRI. Technol Cancer Res Treat 5:401-410

41. Sijens PE, van den Bent MJ, Nowak PJ, van Dijk P, Oudkerk M (1997) $1 \mathrm{H}$ chemical shift imaging reveals loss of brain tumor choline signal after administration of Gd-contrast. Magn Reson Med 37:222-225

42. Sijens PE, Oudkerk M, van Dijk P, Levendag PC, Vecht CJ (1998) 1H MR spectroscopy monitoring of changes in choline peak area and line shape after Gd-contrast administration. Magn Reson Imaging 16:1273-1280

43. Eby PR, Demartini WB, Peacock S, Rosen EL, Lauro B, Lehman CD (2007) Cancer yield of probably benign breast MR examinations. J Magn Reson Imaging 26:950-955

44. Kriege M, Brekelmans CT, Boetes C, Besnard PE, Zonderland HM, Obdeijn IM, Manoliu RA, Kok T, Peterse H, TilanusLinthorst MM, Muller SH, Meijer S, Oosterwijk JC, Beex LV, Tollenaar RA, de Koning HJ, Rutgers EJ, Klijn JG (2004) Efficacy of MRI and mammography for breast-cancer screening in women with a familial or genetic predisposition. N Engl J Med 351:427-437

45. Liberman L, Morris EA, Benton CL, Abramson AF, Dershaw DD (2003) Probably benign lesions at breast magnetic resonance imaging: preliminary experience in high-risk women. Cancer 98:377-388

46. Sadowski EA, Kelcz F (2005) Frequency of malignancy in lesions classified as probably benign after dynamic contrast-enhanced breast MRI examination. J Magn Reson Imaging 21:556-564 